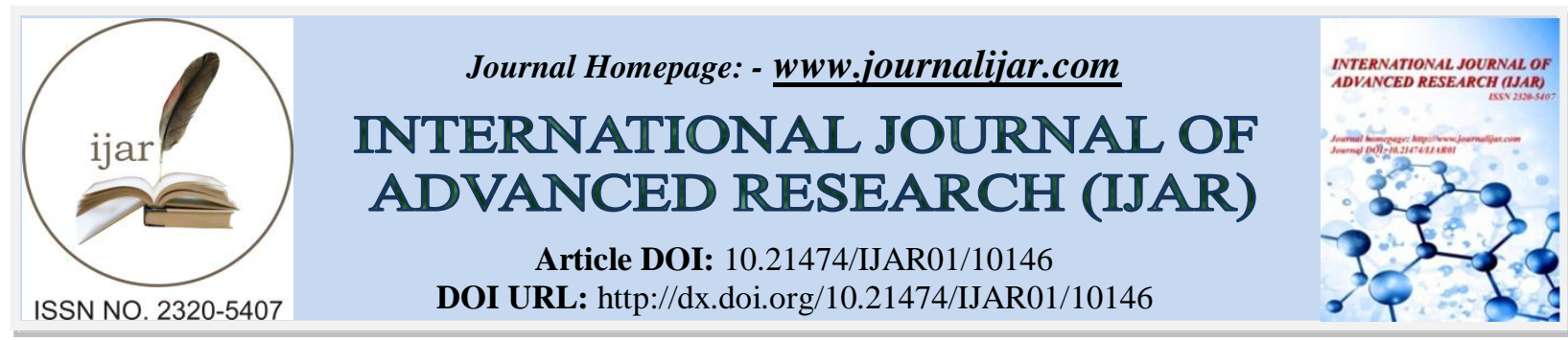

RESEARCH ARTICLE

\title{
CROSS-SECTIONAL IMAGING FEATURES OF COMMON AND UNCOMMON PRIMARY RETROPERITONEAL TUMORS: AN EXPERIENCE AT OUR INSTITUTE - A PICTORIAL ESSAY.
}

\section{Kenjum Riba $^{1}$, Veeraraghavan Gunasekaran ${ }^{1}$, Ngaizavung Hauzel ${ }^{1}$, Sirasanagandla Krishna Bharati ${ }^{1}$ and Meenakumari Ayekpam ${ }^{2}$}

1. Post Graduate Trainees, Department of Radiodiagnosis, Regional Institute of Medical Sciences (RIMS), Imphal, Manipur, 795001, India.

2. Professor and Head of Department, Department of Radiodiagnosis, Regional Institute of Medical Sciences (RIMS), Imphal, Manipur, 795001, India.

\section{Manuscript Info}

\section{Manuscript History}

Received: 01 October 2019

Final Accepted: 03 November 2019

Published: December 2019

\section{Key words:-}

Mesodermal tumors, liposarcoma, Plexiform neurofibroma, sacrococcygeal teratoma.

\section{Abstract}

Primary retroperitoneal tumors are very rare neoplasms accounting for only $0.1-0.2 \%$ of all tumors in the body. They can be either mesodermal, neurogenic, germ cell or lymphoid in origin with mesodermal tumors accounting for $80 \%$ of all primary retroperitoneal neoplasms. Cross-sectional imaging such as computed tomography and magnetic resonance imaging play a vital role in non-invasive assessment and localization of these tumors within the retroperitoneal space as well as for pretreatment staging. Though tissue diagnosis is required for definitive diagnosis due to the overlapping imaging features, certain key imaging features on cross-sectional imaging can help us to narrow down the differential diagnoses. Also imaging helps to guide the site of biopsy due to heterogeneous nature of these tumors. Familiarity with the key cross sectional imaging features of these heterogeneous neoplasms along with clinical and demographic data will facilitate accurate diagnosis and early management of the same.

Copy Right, IJAR, 2019,. All rights reserved.

\section{Introduction:}

Primary retroperitoneal tumors are histologically primitive tumors that arise in the retroperitoneal space which do not include the tumors originating from the retroperitoneal organs such as pancreas, adrenal glands, organs of the excretory system, ascending and descending colon or metastatic lesions. ${ }^{1,2}$ They are very rare and account for only $0.1-0.2 \%$ of all malignancies and $70 \%-80 \%$ are malignant in nature. ${ }^{3,4}$ Primary retroperitoneal tumors are classified according to the tissue of origin in the retroperitoneal space (mesodermal, neurogenic, germ cell, sex cord and stromal, lymphoid or hematologic) ${ }^{4}$. Mesodermal tumors are accounting for $80 \%$ of primary retroperitoneal neoplasms, whereas neurogenic tumors are relatively less common, accounting for $10 \%$ of the primary retroperitoneal neoplasms. ${ }^{3,4}$ Noninvasive evaluation of these tumors by computed tomography (CT) and magnetic resonance imaging (MRI) is necessary due to the variable treatment options. Both the modalities are helpful in both characterization as well as in assessing the extent of the disease and in staging. Presence of calcification within these tumors is best assessed by CT whereas MRI is helpful for the assessment of fat containing lesions and vascular invasion by these tumors due to the superior soft tissue contrast. ${ }^{4}$ Although tissue diagnosis plays an inevitable role for the final diagnosis of these tumors and overlap in the imaging features of retroperitoneal tumors, distinctive characteristics of some of the neoplasms on imaging are helpful in narrow down the differential diagnosis. 
Familiarity with the CT and MR imaging features of various retroperitoneal masses will facilitate accurate diagnosis as well as staging of these lesions.

This pictorial essay reviews the imaging features of few of the histopathologically confirmed common and uncommon primary retroperitoneal tumors presented to our institute from 2016 to 2019.

\section{Anatomy of retroperitoneum}

The retroperitoneum is a compartmentalized space extending between transversalis fascia posteriorly and posterior parietal peritoneal layer anteriorly [Fig. 1]. It is divided into following three potential spaces: a) Anterior pararenal space, b) posterior pararenal space c) perirenal space and d) great vessel space. Anterior pararenal space is bounded anteriorly by posterior parietal peritoneum, posteriorly by anterior renal fascia / Gerota's fascia and laterally by lateroconal fascia which is a continuation of posterior renal fascia / Zuckerkandl fascia Anterior pararenal space is subdivided into (i) pancreaticoduodenal space comprising pancreas and second, third and fourth portions of the duodenum, and (ii) pericolonic space comprising ascending and descending colon, lymph nodes and fat. Anterior pararenal space is continuous across the midline. Posterior pararenal space extends between Zuckerkandl fascia anteriorly and transversalis fascia posteriorly and contains only small amounts of fat. The perirenal space is situated between anterior and posterior renal fasciae and contains adrenal gland, kidney and renal pelvis, proximal ureter, renal hilar vessels, lymph nodes, and fat. The perirenal space contains bridging septa and a network of lymphatic vessels that allow the spread of disease to or from adjacent spaces. There are three more potential expansile planes composed of apposed layers of embryonic mesentery formed from laminations of renal and lateroconal fasciae: (i) retromesenteric, (ii) retrorenal and (iii) lateroconal planes, formed by splitting of anterior renal fascia, posterior renal fascia and lateroconal fascia respectively. The great vessel space is a fat containing space located anterior to psoas muscles and vertebral bodies that surrounds the aorta and inferior vena cava. A fifth space, the infrarenal retroperitoneal space is formed by the fusion of anterior and posterior pararenal spaces, below the level of the kidneys and is communicating with the prevesical and extraperitoneal compartments of the pelvis. ${ }^{4,5,6,7}$

\section{Locating The Tumor Within The Retroperitoneal Space ${ }^{2,8}$}

Origin of a tumor/mass from a retroperitoneal organ should be excluded in order to classify that tumor/mass as a "Primary retroperitoneal mass." The following signs help to locate the mass within the retroperitoneal space [Fig. 2]:

\section{Beak sign:}

A primary retroperitoneal mass/lesion will abut and compress the adjacent organ and form obtuse angles with that organ. Whereas, a mass originating from an organ will form acute angles with that organ thus deforming the edge of that organ into a "beak" or "claw" shape.

\section{Phantom / Invisible organ sign:}

A small retroperitoneal organ may not be visible at all if a large mass is arising from it. This is called as "phantom/invisible organ sign." Absence of this sign indicates a primary retroperitoneal pathology.

\section{Embedded organ sign:}

A mass, not originating from an adjacent hollow viscus / plastic organ (inferior vena cava) will simply compress the organ into a crescentic shape (negative embedded organ sign). In ontrast, when part of an organ appears to be embedded in the mass, it indicates that the mass is arising from that organ (positive embedded organ sign).

\section{Mesodermal Tumors}

These tumors are large at the time of presentation with involvement of adjacent structures with very high recurrence rate. Pseudocapsule may be appreciated due to compression of adjacent structures. Metastases to liver, lung, bones and brain can occur. Liposarcoma, leiomyosarcoma, malignant fibrous histiocytoma, rhabdomyosarcoma, angiosarcoma and sarcoma of perivascular cells are few of the tumors of mesodermal origin. ${ }^{4}$

\section{Liposarcoma}

Liposarcoma is the most common sarcoma of the retroperitoneum arising from deeper soft tissue of the retroperitoneum. It is the second most common adult soft tissue sarcoma. The World Health Organization (WHO) divides liposarcomas into four subtypes: well-differentiated, myxoid, dedifferentiated, and pleomorphic. The most common subtype is well-differentiated retroperitoneal liposarcoma which shows attenuation similar to macroscopic fat on computed tomography CT. On magnetic resonance imaging (MRI), they follow the signal intensity of 
subcutaneous fat with loss of signal on fat suppressed images. They show little or no contrast enhancement on postcontrast study reflecting the paucity of intratumoral vessels. Occasionally, thickened irregular septa, minor nodular and sclerosing components may show homogeneous enhancement. Imaging features that favor well-differentiated liposarcoma over lipoma include large lesion size $(>10 \mathrm{~cm})$, presence of thick septa $(>2 \mathrm{~mm})$, nodular and/or globular areas, nonadipose mass like areas, and a decreased percentage of fat composition ( $<75 \%$ fat in mass). ${ }^{5}$ Although areas of necrosis and calcification tend to be uncommon in liposarcomas, $30 \%$ of the cases may show calcification, which is an important sign of dedifferentiation. ${ }^{4}$ [Fig. 3]

Dedifferentiated liposarcomas show areas with attenuation and signal intensity similar to well-differentiated liposarcoma with more mass like areas of nonfatty tissue and relatively higher attenuation on CT with low T1 and high T2 signal on MRI. ${ }^{5}$ Myxoid liposarcomas present in younger age group in comparison to well-differentiated and dedifferentiated types. On CT, they have heterogeneous hypoattenuating appearance with relatively lesser attenuation than that of muscle. A "pseudocystic" appearance is characteristic due to the homogeneous distribution of fat and soft tissue within the mass. High mucopolysaccharide contents give strikingly high T2 signal intensity on MRI along with lacy, linear / amorphous areas fat signal intensity on both T1 and T2 weighted images. Pleomorphic liposarcomas present as heterogeneous soft-tissue masses with areas of necrosis. Small foci of fat can be appreciated even in solid-appearing lesions on MRI. ${ }^{4}$

\section{Solitary fibrous tumor}

Solitary fibrous tumors (SFTs) are very rare tumors of the retroperitoneum with only very few cases reported in the literature. Age of onset varies from 17 to 85 years with a female predilection. On cross sectional imaging, they appear as large, lobulated, round to oval shaped masses, deforming the adjacent organs. Most of the SFTs of the retroperitoneum are pseudoencapsulated / enveloped which is characteristic of these tumors. On computed tomography they are iso/hyperdense to the muscle with density increases as the cell mass increases and density decreases as the amount of collagen mass increases. They may become heterogeneous due to cystic/myxoid degeneration and necrosis. On post contrast study these tumors show three patterns of enhancement: mild $(<50 \%)$, moderate (50-100\%) and significant (>100\%) depends on the amount of cell mass with necrosis more commonly occur in the latter. Sustained and heterogeneous enhancement maybe noted on delayed phase. Pseudoenvelope also shows variable degree of enhancement [Fig. 4]. On MRI, they have iso- hyperintensity to muscle on T1W images with T2 signal depends on the amount of collagen (low signal), cell mass and myxoid degeneration (high signal). ${ }^{9,10}$

\section{Neurogenic Tumors}

Neurogenic tumors account for $10-20 \%$ of primary retroperitoneal tumors. They are usually benign in nature with better prognosis in comparison to sarcomas. ${ }^{3,4}$ They can originate from (a) ganglion cell (ganglioneuromas, ganglioneuroblastomas, neuroblastomas), (b) paraganglionic system/chromaffin tissue (pheochromocytomas, paragangliomas), and (c) nerve sheath (neurilemmomas, neurofibromas, neurofibromatosis, malignant nerve sheath tumors). ${ }^{4,11}$

\section{Neurofibroma}

Neurofibromas are benign peripheral nerve sheath tumor composed of nerve sheath cells intermingled with thick collagen bundles with a small to moderate amount of myxoid degeneration accounting for about $1 \%$ of retroperitoneal tumors. ${ }^{3,11}$ In patients with neurofibromatosis they commonly occur in deep anatomical locations. ${ }^{5}$ Retroperitoneal neurofibromas appear as well-defined, round, hypodense, inhomogeneous solid masses on CT, seen along the expected course of the nerve. On non-contrast CT, they have attenuation values of 20-25 HU with homogeneous enhancement $(30-50 \mathrm{HU})$ on contrast-enhanced CT. Centrally located nervous tissue shows T1 high and T2 low signal whereas peripherally located myxoid tissue shows T1 low and T2 high signal on MR imaging. ${ }^{11}$ Plexiform neurofibroma is an uncommon variant of neurofibromatosis type 1 occurring along multiple nerves and their branches as an interdigitating network of fingerlike fronds. ${ }^{12,13}$ Retroperitoneal plexiform neurofibromas appear as symmetric,bilateral parapsoas or presacral masses along the distribution of lumbosacral plexus. High lipid content, high water content within the mucinous matrix, cystic degeneration and entrapment of perineural adipose tissue are contributing to the hypodensity of these tumors ${ }^{13}$ [Fig.5].

\section{Paraganglioma}

Paraganglia are highly vascularized specialized neural crest cells that are symmetrically distributed along the aortic axis in close association with the sympathetic chain in the neck, chest, abdomen, and pelvis. Tumors arising from these cells are called paragangliomas with the most common location being the organ of Zuckerkandl located along 
the aorta at the level of the origin of the inferior mesenteric artery. ${ }^{4,5}$ The rate of malignant transformation is higher in paragangliomas in comparison to pheochromocytomas. ${ }^{3}$ On unenhanced CT, small tumors appear as wellcircumscribed, lobular or round soft tissue-attenuating homogeneous masses whereas larger tumors are heterogeneous in appearance. Fluid-fluid level can be appreciated due to hemorrhage. Intense contrast enhancement is the rule due to the hypervascular nature of these tumors ${ }^{4,5}[$ Fig. 6]. On MRI, they exhibit variable signal intensity on T2-weighted image with signal voids can be appreciated in T1-weighted spin-echo sequences. ${ }^{4}$

\section{Ganglioneuroma}

It is a benign neoplasm composed of ganglion cells and Schwann cells. Most common locations include posterior mediastinum, retroperitoneum, adrenal glands, head and neck soft tissues. Solitary tumors are diagnosed before 10 years of age and has a female predilection with female: male ratio of $3: 1^{17}$.

\section{Retroperitoneal composite malignant paraganglioma-ganglioneuroma}

These are very rare tumors with only very few cases reported and few in the urinary bladder ${ }^{17}$. Composite paragangliomas have one of the neural components such as neuroblastoma, ganglioneuroblastoma, or typical ganglioneuroma ${ }^{18}$. These tumors appear as large heterogenous well defined masses showing intense enhancement with cystic areas on post contrast CT images [Fig.7].

\section{Germ Cell, Sex Cord And Stromal Tumors}

Extragonadal germ cell tumors (EGCT) account for 1-3\% of all germ cell tumors and less commonly located in the retroperitoneum second only to the most common location, the mediastinum. ${ }^{5}$ They are usually located in or near the midline between T6 and S2 vertebrae with a midline mass more suggestive of a primary extragonadal germ cell tumor rather than of metastasis. ${ }^{4}$

\section{Teratoma}

Teratomas represent $11 \%$ of all primary retroperitoneal tumors and is the third most common tumor in the retroperitoneum in children, after neuroblastoma and Wilms tumor ${ }^{4}$. They can be either mature or immature, and benign/malignant. Mature teratomas, also called as dermoid cysts, are well-differentiated tumors derived from at least two of the three germ cell layers (ectoderm, mesoderm, endoderm). Imaging features favouring mature teratoma is the presence of a fat-containing retroperitoneal cyst with mural calcifications. Wall thickening, irregular margins, and infiltration of adjacent organs are the signs of malignant transformation of mature teratomas. Immature teratomas appear as predominantly solid with coarse and ill defined areas of calcification and scattered areas of fat. Mature and immature teratomas may not be differentiated by imaging alone. ${ }^{4,8}$

Preascral space is one of the pelvic retroperitoneal spaces with teratoma as one of the fat-containing tumors that occurs in this space. Sacrococcygeal teratomas are more common in infans and children with very few cases have been reported in adults with female:male ratio of 4:1. ${ }^{14}$ They may grow either anterosuperiorly into the abdominopelvic cavity and/or posteroinferiorly into the gluteal region. Sacrococcygeal teratomas can occur either predominantly external or exclusively presacral without external component with later presenting late in life than with the external component. They have varied appearances on CT and MR imaging, ranging from heterogeneous solid to cystic with or without septations with areas of intratumoral fat and calcification [Fig.8]. Adult sacrococcygeal teratomas are more prone for malignancy than those occurring in children. ${ }^{15.16}$

\section{Lymphoid Neoplasms}

\section{Lymphoma}

Lymphomas are accounting for $1 / 3^{\text {rd }}$ of all primary retroperitoneal tumors. Extranodal or para-aortic lymph nodal involvement is more common in non-Hodgkin's lymphoma (55\% of cases) than Hodgkin's lymphoma. ${ }^{3}$ Lymphomas appear as well-defined, homogeneous masses that spread between normal structures without compressing them [Fig.9]. "Floating aorta" or "CT angiogram" sign can be appreciated on cross-sectional imaging due to anterior displacement of aorta and IVC. On MR imaging they appear as isointense on T1-weighted images and iso-to hyperintense on T2 weighted images. ${ }^{4}$ The homogeneous appearance is the main distinguishing factor that differentiates lymphomas from other primary retroperitoneal masses, however $23 \%$ of cases may have heterogeneous appearance thus may be difficult to differentiate from other nonlipomatous primary retroperitoneal tumors. 
Key imaging features

\begin{tabular}{|c|c|c|}
\hline Cell / tissue of origin & Tumor & Key imaging features \\
\hline Adipose tissue & Liposarcoma & $\begin{array}{lr}\text { Large mass } & \text { with } \\
\text { attenuation/intensity similar } & \text { to } \\
\text { macroscopic fat on CT/MRI. Non- } \\
\text { fatty tissue components with } \\
\text { calcification favors } \\
\text { dedifferentiation. }\end{array}$ \\
\hline Fibroblasts/Myofibroblasts & Solitary fibrous tumor & $\begin{array}{l}\text { Well-defined, gently lobulated, } \\
\text { pseudoencapsulated mass with } \\
\text { intense heterogeneous enhacement } \\
\text { on arterial phase, persisting on } \\
\text { delayed phase. }\end{array}$ \\
\hline Nerve sheath & Neurofibroma & $\begin{array}{l}\text { Well-defined, round, hypodense, } \\
\text { inhomogeneous solid masses on CT, } \\
\text { seen along the expected course of } \\
\text { thenerve.Retroperitoneal plexiform } \\
\text { neurofibromas appear as symmetric, } \\
\text { bilateral parapsoas or presacral } \\
\text { masses along the distribution of } \\
\text { lumbosacral plexus. }\end{array}$ \\
\hline $\begin{array}{llll}\text { Paraganglia } \\
\text { Zuckerkandl }\end{array}$ & $\begin{array}{l}\text { Paraganglioma } \\
\begin{array}{l}\text { Composite paraganglioma- } \\
\text { ganglioneuroma }\end{array}\end{array}$ & $\begin{array}{l}\text { Homogeneous (small tumors) } \\
\text { heterogeneous (large tumors) masses } \\
\text { with intense enhancement. Fluid- } \\
\text { fluid levels can be appreciated due } \\
\text { to hemorrhage. } \\
\text { Large heterogeneously enhancing } \\
\text { mass with cystic non-enhancing } \\
\text { areas. }\end{array}$ \\
\hline Germ cell & Mature / immature teratoma & $\begin{array}{l}\text { Mature teratoma }- \text { Fat containing } \\
\text { retroperitoneal cyst with mural } \\
\text { calcifications } \\
\text { Immature teratoma - Solid } \\
\text { heterogeneous mass with areas of fat } \\
\text { attenuation and calcification } \\
\text { Sacrococcygeal teratoma - Presacral } \\
\text { mass with / without external } \\
\text { component with above mentioned } \\
\text { imaging features }\end{array}$ \\
\hline Lymphoid tissue & Lymphoma & $\begin{array}{l}\text { Homogeneous masses spreading } \\
\text { between the normal structures } \\
\text { without compressing them }\end{array}$ \\
\hline
\end{tabular}

Table 2:- Primary Retroperitoneal (PRP) Masses with peculiar imaging features

\begin{tabular}{|l|l|}
\hline Fat containing PRP masses & Liposarcoma, Teratoma \\
\hline PRP masses with calcification & Teratoma, Dedifferentiated liposarcoma \\
\hline Hypervascular PRP mass & Paraganglioma \\
\hline Heterogeneously enhancing PRP mass & Composite paraganglioma-ganglioneuroma \\
\hline Mantle-like PRP mass & Lymphoma \\
\hline
\end{tabular}

\section{Conclusion:-}

Primary retroperitoneal neoplasms are diverse group of rare neoplasms. Though definitive diagnosis of these neoplasms done by tissue sampling, cross-sectional imaging is a vital non-invasive tool to locate these tumors within the retroperitoneal space by some key imaging features as well as for pretreatment staging. 


\section{Conflicts of interest:}

Nil.

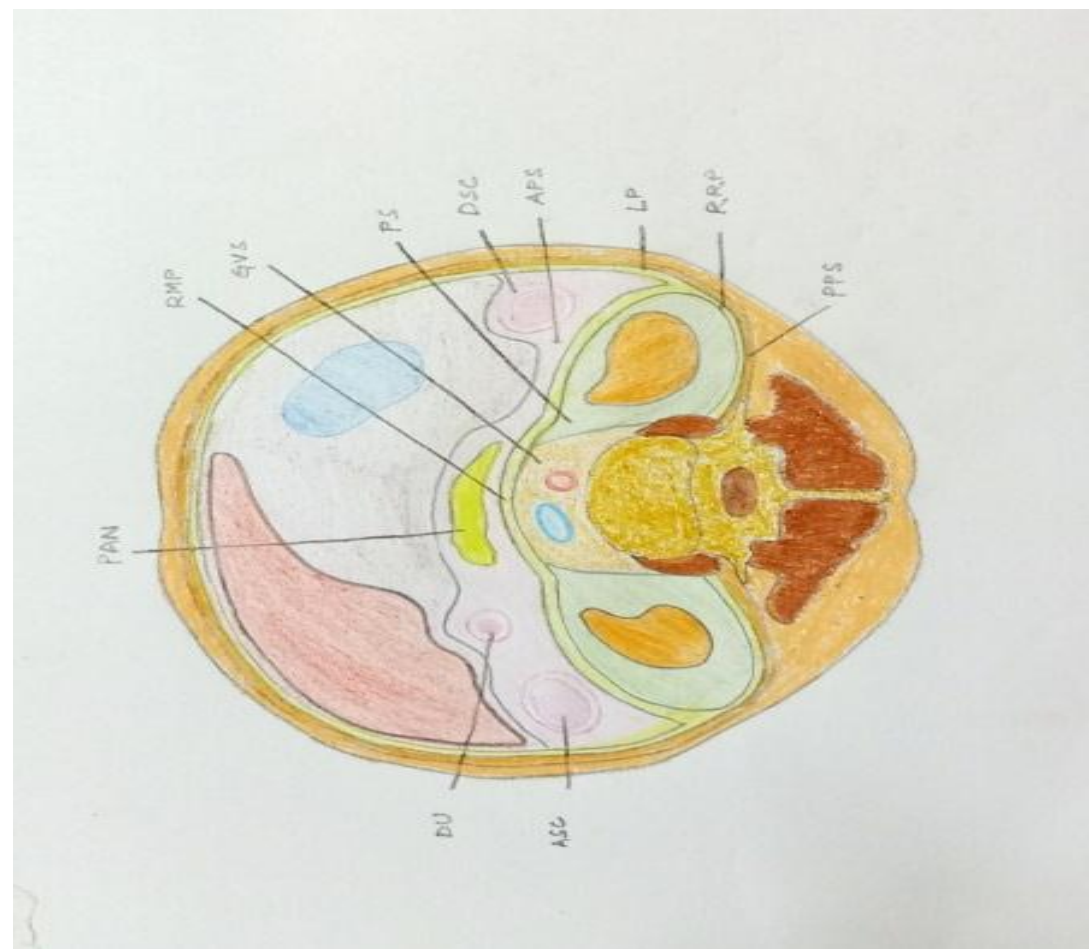

Figure 1:- Anatomy of the retroperitoneum and interfascial planes. APS - Anterior Pararenal Space, PPS Posterior Pararenal Space, PS - Perirenal Space, GVS - Great Vessel Space, RMP - Retromesenteric Plane, RRP Retrorenal Plane, LP - Lateroconal plane. APS comprises Pancreaticoduodenal space (contains DU - Duodenum and PAN - Pancreas) and Pericolonic space (contains ASC - Ascending colon and DSC - Descending colon).

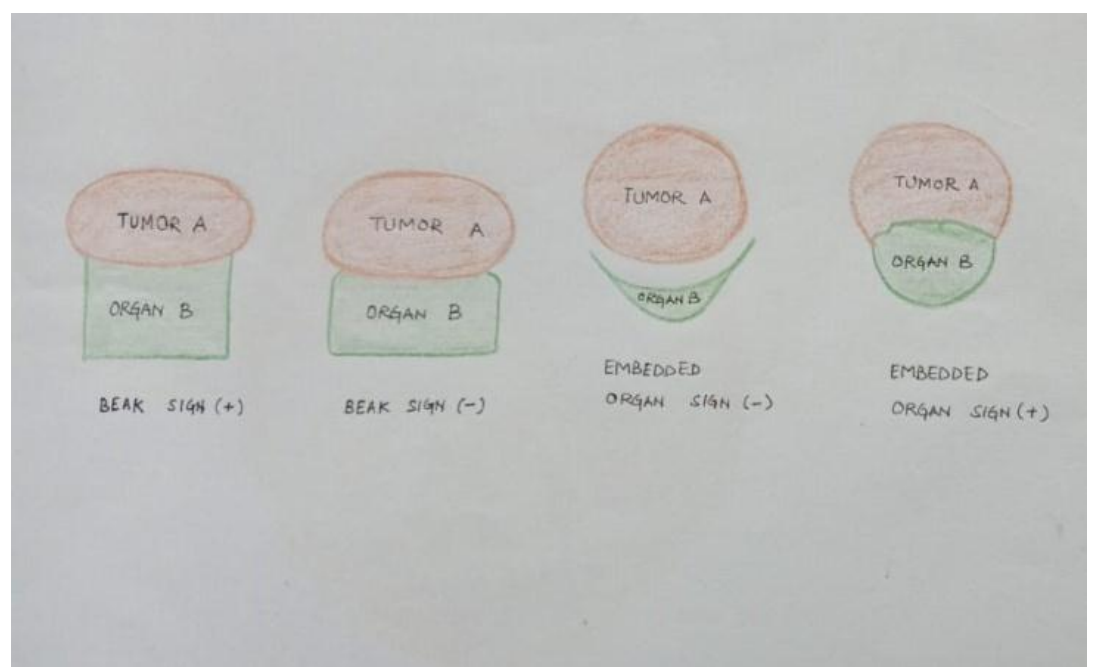

Figure 2:- Signs that help to locate the mass within the retroperitoneal space (Beak sign and embedded organ sign) 

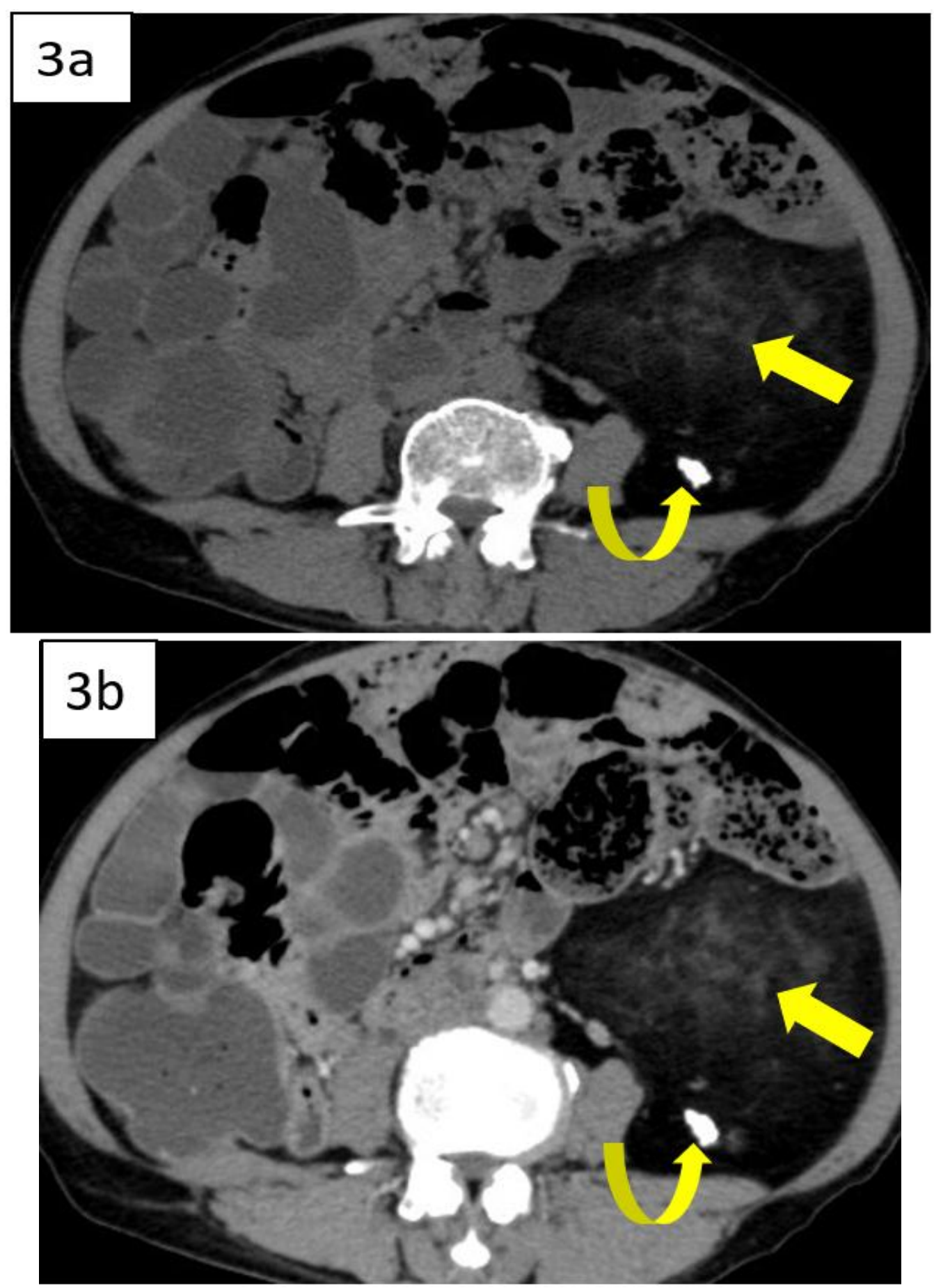


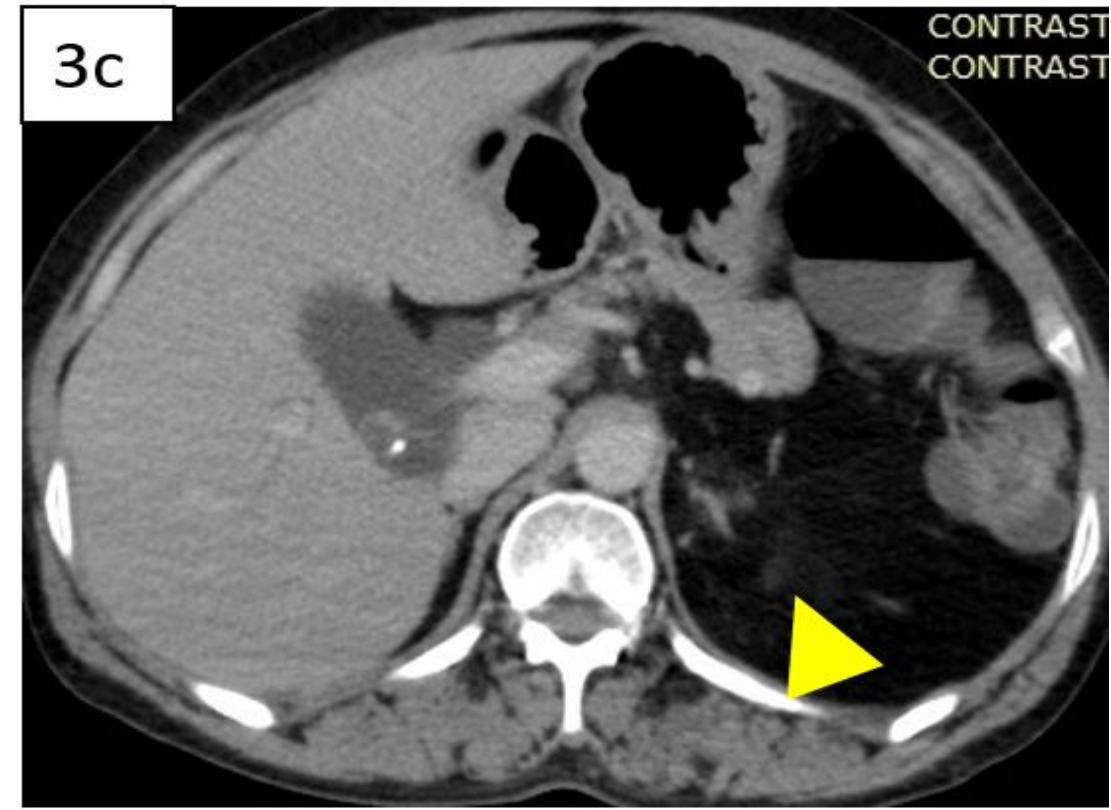

Figure 3:- Well-differentiated liposarcoma in a 55 year old female patient. Axial plain (3a) and csontrast-enhanced CT (3b) images show a large fat-containing left retroperitoneal mass with enhancing solid components (straight arrows) and coarse calcification (curved arrows). Contrast-enhanced axial CT (3c) of the same patient taken one year after surgery shows fat-containing mass with solid components (arrowhead) suggestive of recurrence.
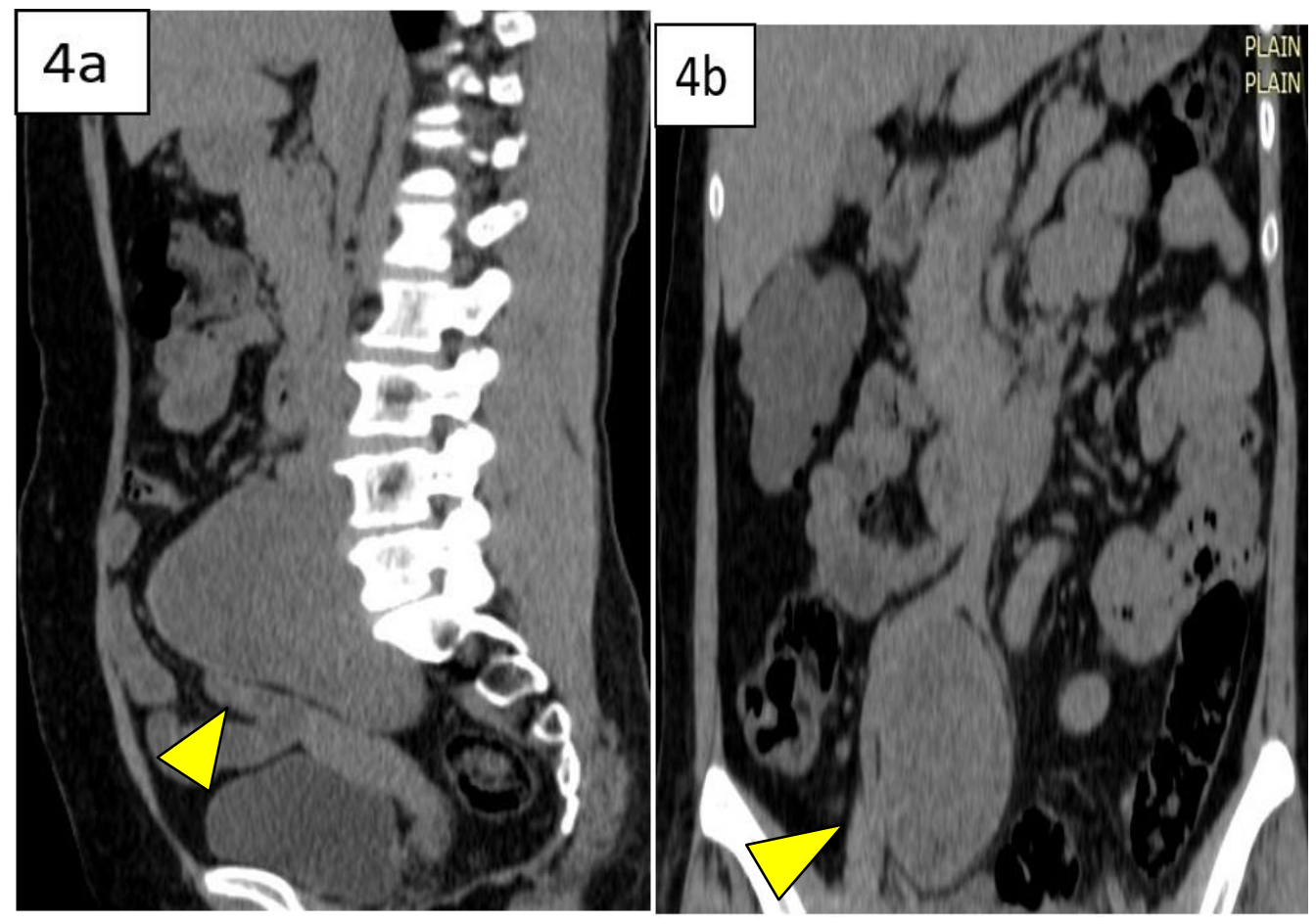


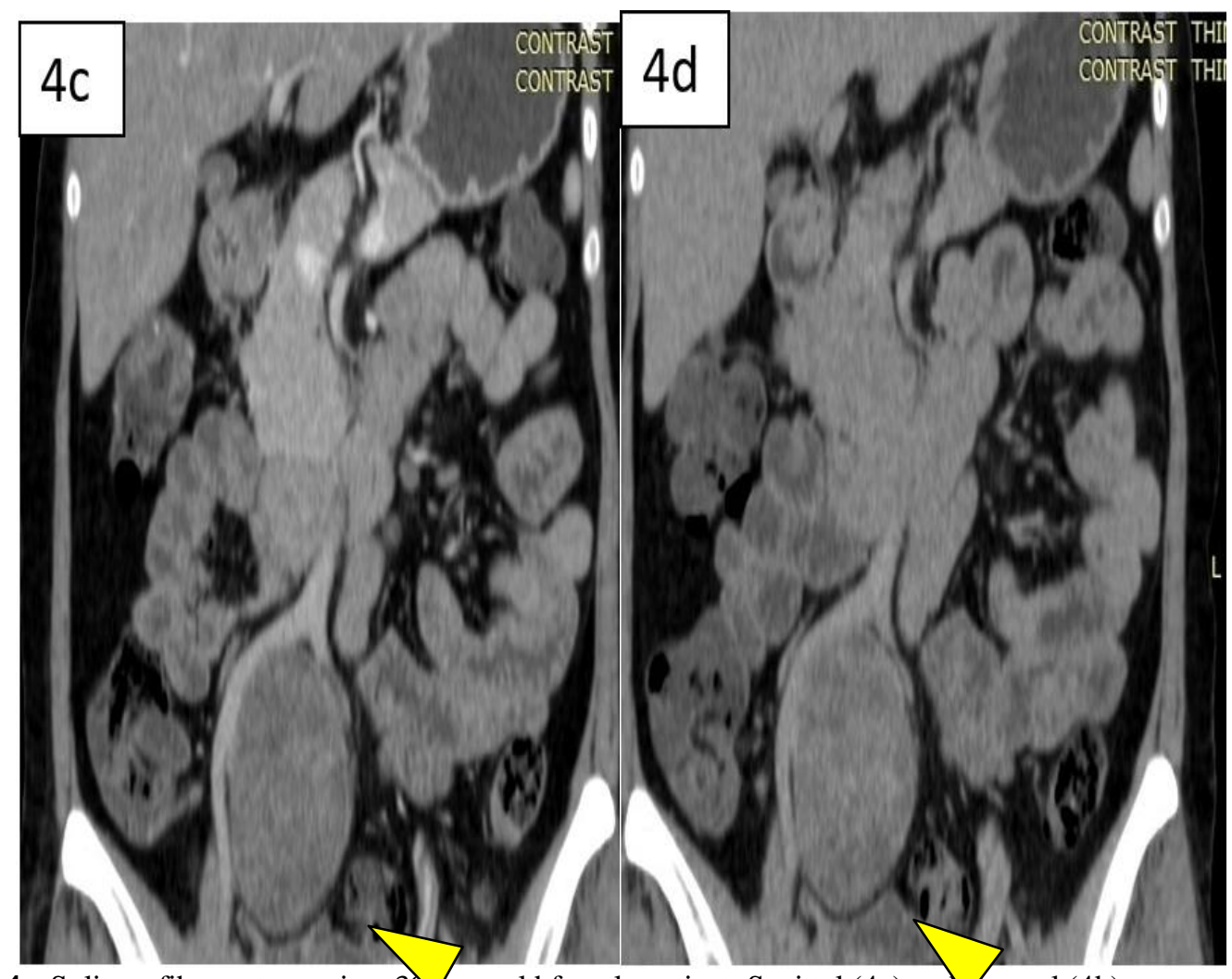

Figure 4:- Solitary fibrous tumor in a 32year-old female patient. Sagittal (4a) and images of the abdomen shows a well-defined, gently lobulated, oval shaped, pseudoencapsulated / enveloped solid and cystic, heterogeneous mass leison involving the inferior retroperitoneal space splaying the aortic bifurcation and extending into the extraperitoneal spaces of the pelvis. Post-contrast study (4c, 4d) shows enhancement of the envelope and moderate enhancement of the solid components of the lesion on portal phase (4c) with sustained heterogeneous enhancement on delayed phase (4d).

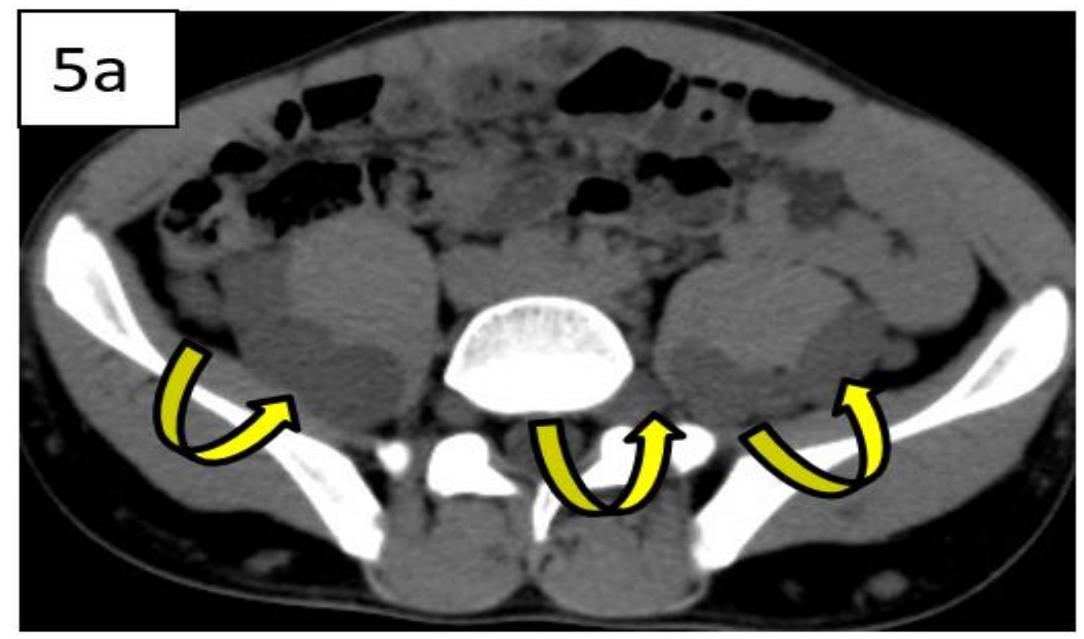




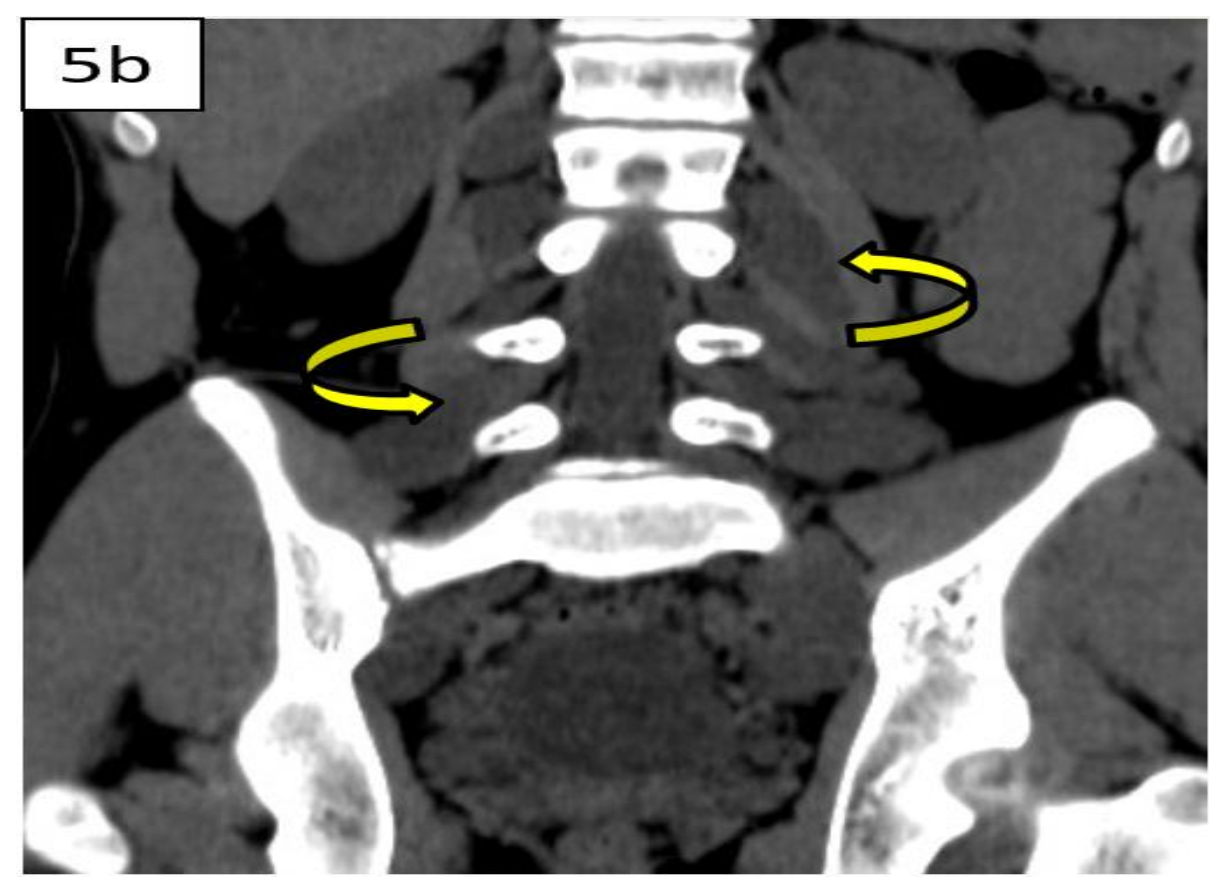

Figure 5: Plexiform neurofibroma in a 15-year-old male patient. Axial (5a) and coronal (5b) non-contrast CT images of the abdomen shows multiple bilateral, symmetrical, round to oval shaped, hypodense parapsoas and presacral masses (curved arrows) distributed along the lumbosacral plexus.

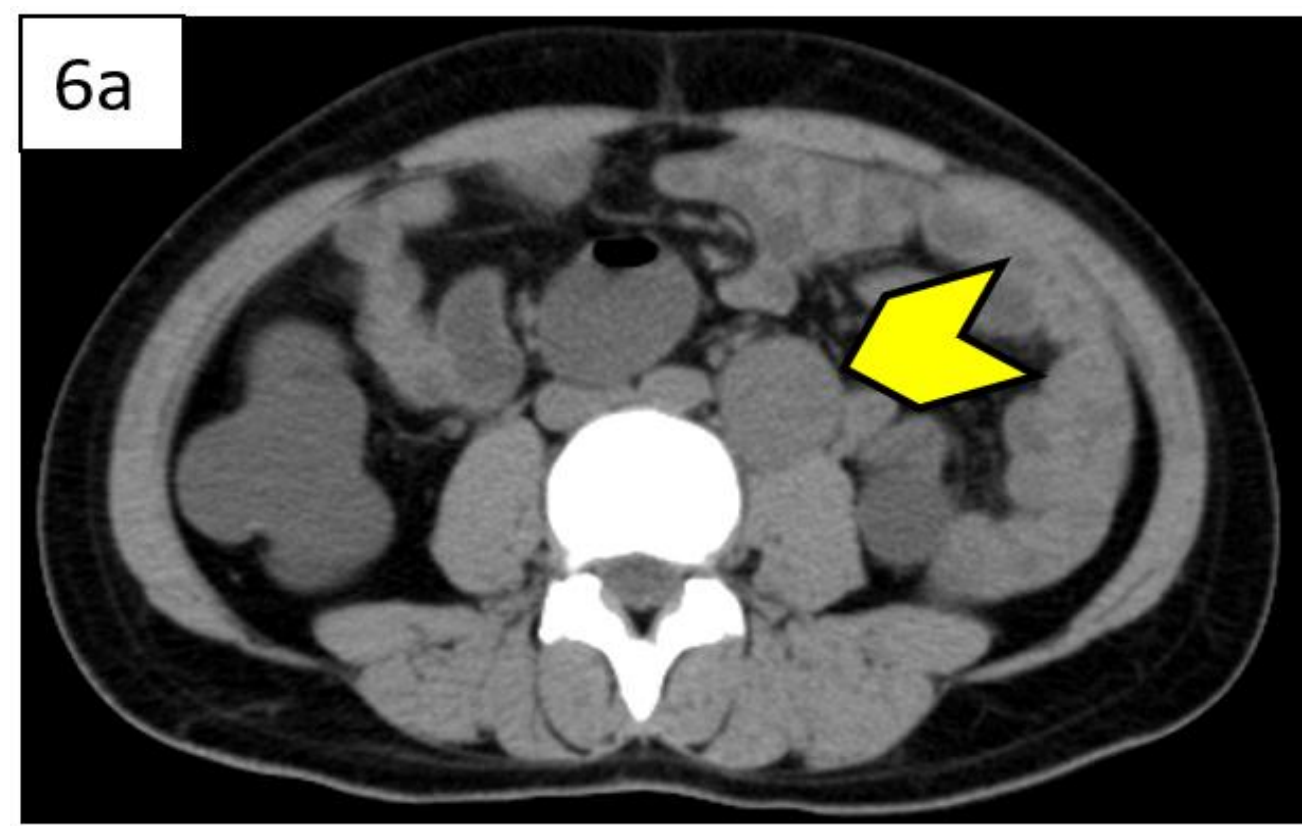



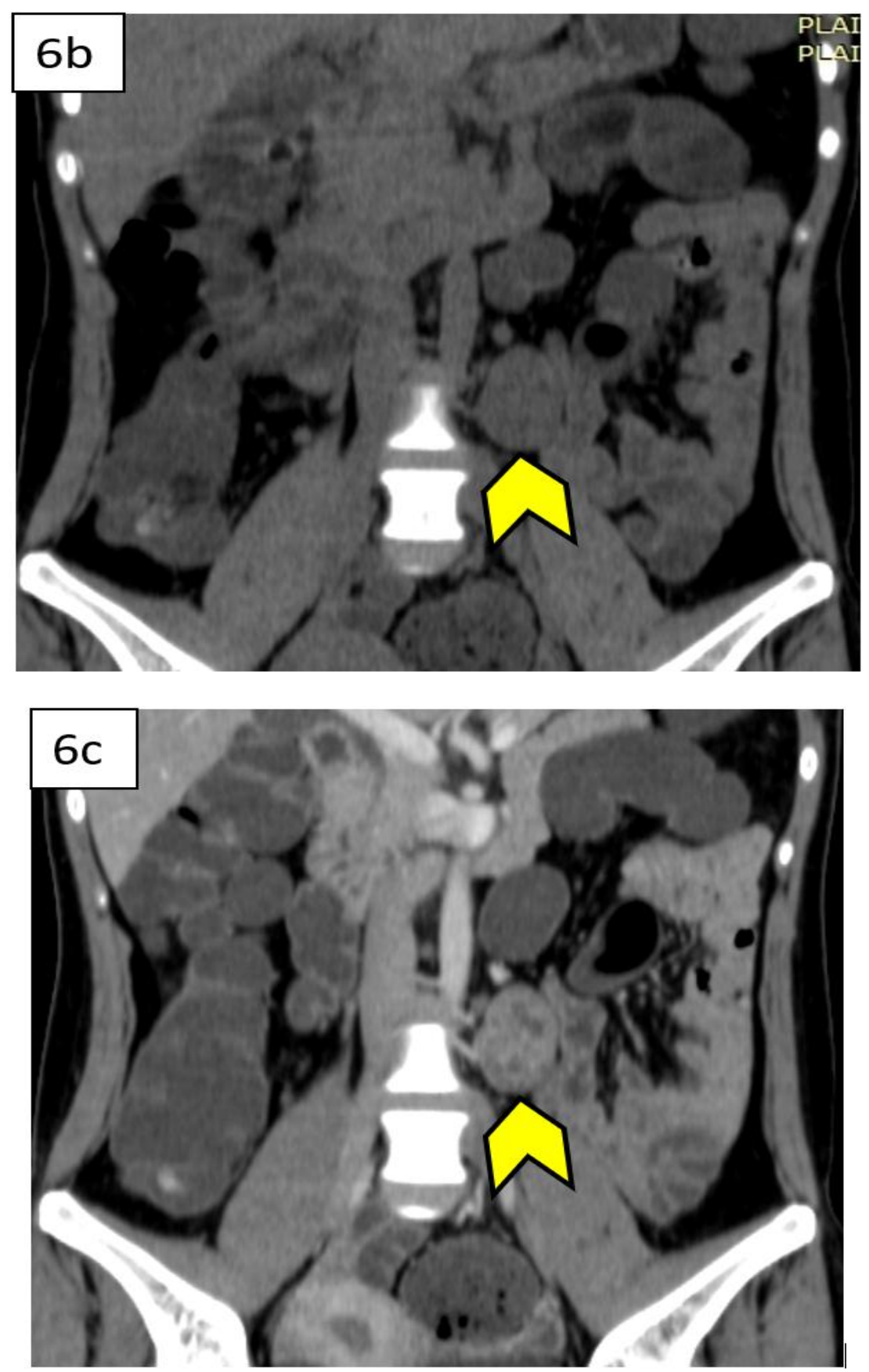

Figure 6:- Paraganglioma in a 23-year-old female patient. Axial (6a) and coronal (6b) plain CT images of the abdomen show a well-defined, oval shaped, gently lobulated, heterogeneous mass lesion (chevron) in the great vessel space to the left of lower abdominal aorta exhibiting intense heterogeneous enhancement on post-contrast $\operatorname{study}(6 \mathrm{c})$. 

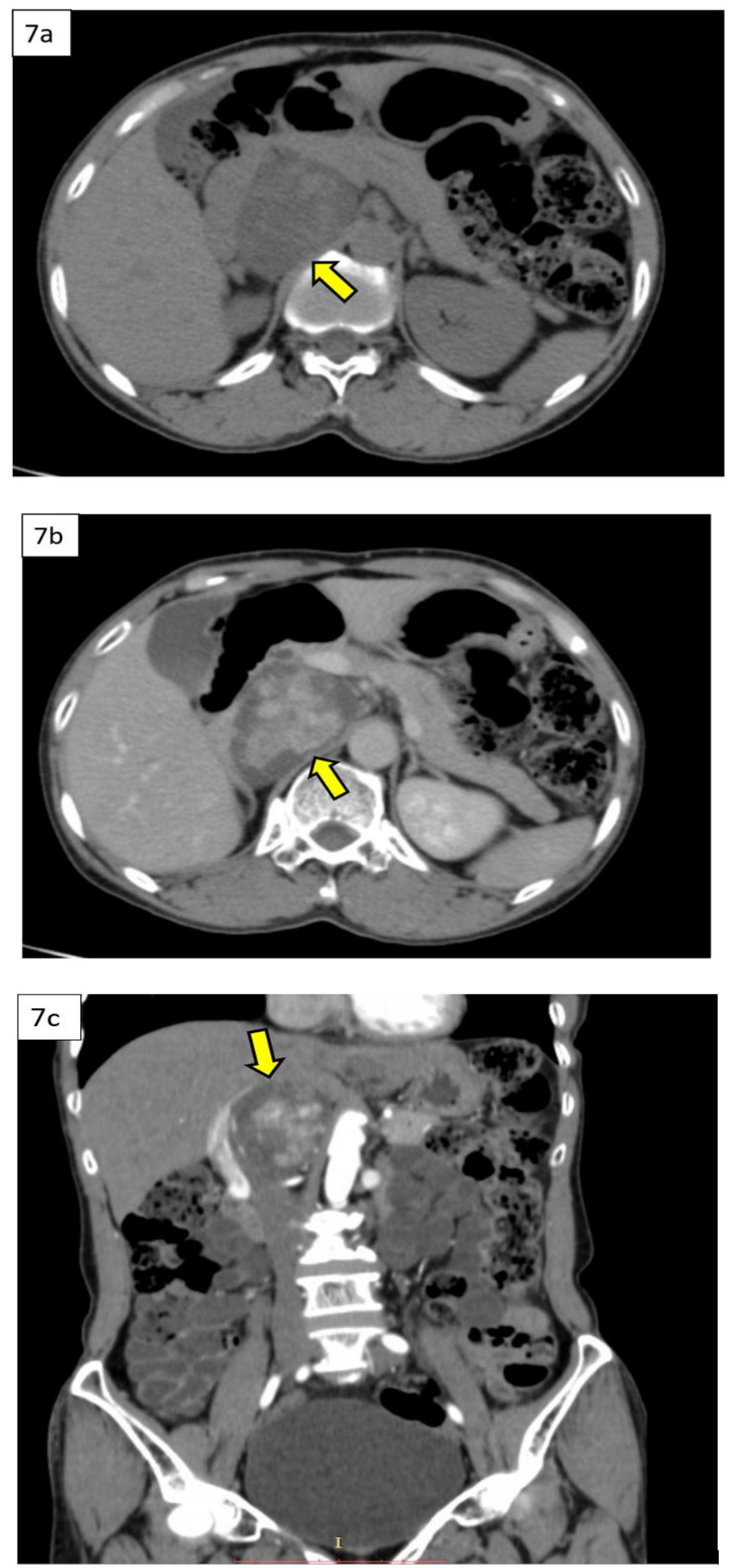

Figure 7:- Composite retroperitoneal malignant paraganglioma-ganglioneuroma in a 30 year old female. Axial (7a) non-contrast CT image of abdomen shows a well defined large heterogenous mass (arrows) in right retroperitoneum with compression of the IVC and the portal vein. Axial (7b) and coronal (7c) post contrast study shows heterogenous enhancement with peripheral non-enhancing cystic areas. 

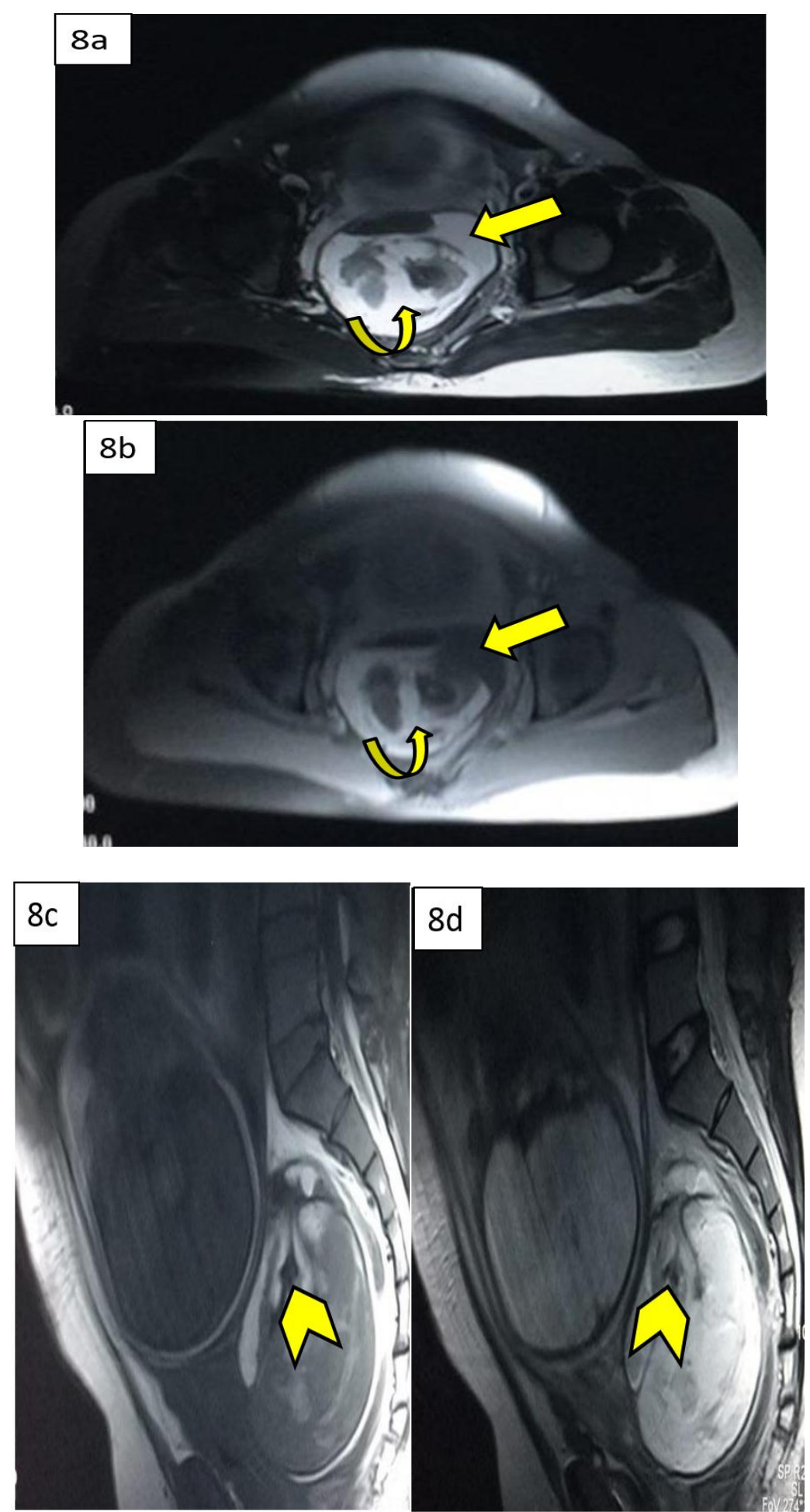

Figure 8:- Sacrococcygeal teratoma in a 27-year-old female patient. Axial T2-weighted images (8a) of the pelvis shows a round to oval shaped, heterogeneous mass lesion involving the presacral space with fluid (curved arrows) not suppressed on fat suppressed images and fat (straight arrows) suppressed on fat-suppressed images ( $8 \mathrm{~b}$ ). A signal void (chevrons) also noted on both T1 and T2 weighted sagittal images (8c and 8d) suggestive of calcification. 

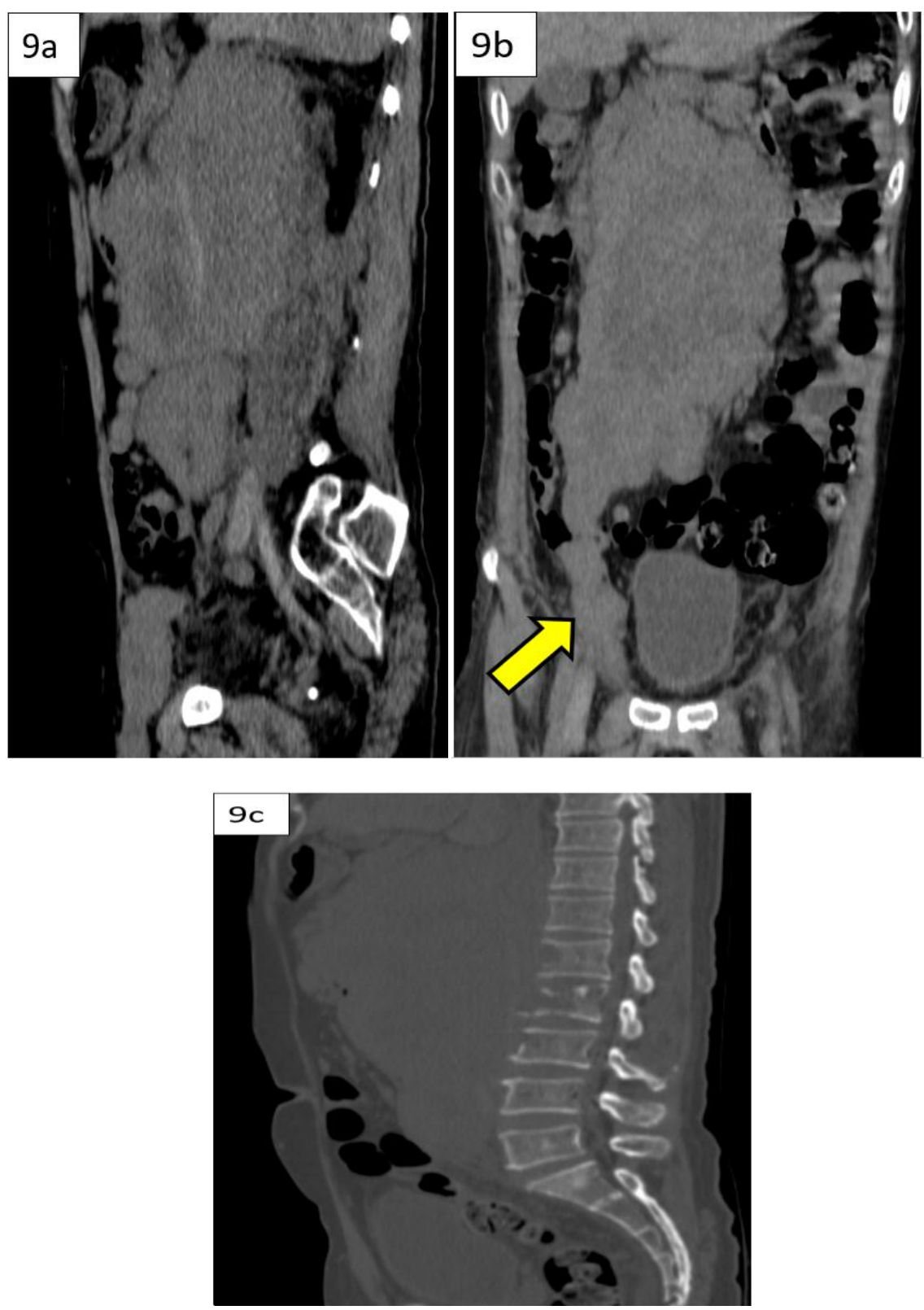

Figure 9:- Non-Hodgkin's lymphoma in a 56-year-old male patient. Sagittal (9a) non-contrast images of the abdomen show a large, confluent, relatively homogeneous, lobulated mass lesion involving the retroperitoneum with extension between the great vessels and spine with erosion of the vertebral bodies (9c). Right inguinal extension (arrow) is also noted in the coronal image (9b). Contrast study was not done due to the deranged renal function tests.

\section{References:-}

1. Carbognin G., Pinali L., Procacci (†) C. Retroperitoneal tumors. In: Gourtsoyiannis N.C., Ros P.R., editors. Radiologic-Pathologic Correlations from Head to Toe. 1st ed. Heidelberg: Springer; 2005. p. 619-643.

2. Nishino M, Hayakawa K, Minami M, Yamamoto A, Ueda H, Takasu K. Primary retroperitoneal neoplasms: CT and MR imaging findings with anatomic and pathologic diagnostic clues. Radiographics 2003 JanFeb;23(1):45-57.

3. Neville A1, Herts BR. CT characteristics of primary retroperitoneal neoplasms. Crit Rev ComputTomogr 2004;45(4):247-70.

4. Rajiah P, Sinha R, Cuevas C, Dubinsky TJ, Bush WH Jr, Kolokythas O. Imaging of uncommon retroperitoneal masses. Radiographics 2011 Jul-Aug;31(4):949-76. 
5. Torigian DA, Ramchandani P. Retroperitoneum. In: Haaga JR, Boll DT, editors. CT and MRI of the whole body. 6th ed. Philadelphia: Elsevier; 2017. p. 1862-1939.

6. Hari S, Kumar A. The retroperitoneum. In: Khandelwal N, Chowdhury V, Gupta AK, editors. Diagnostic radiology: genitourinary imaging. 3rd ed. New Delhi: Jaypee Brothers Medical Pulblishers; 2009. p. 408-434.

7. Tirkes T, Sandrasegaran K, Patel AA, Hollar MA, Tejada JG, Tann M, et al. Peritoneal and retroperitoneal anatomy and its relevance for cross-sectional imaging. Radiographics 2012 Mar-Apr;32(2):437-51.

8. Scali EP, Chandler TM, Heffernan EJ, Coyle J, Harris AC, Chang SD. Primary retroperitoneal masses: what is the differential diagnosis? Abdom Imaging 2015 Aug;40(6):1887-903.

9. Shanbhogue AK, Prasad SR, Takahashi N, Vikram R, Zaheer A, Sandrasegaran K. Somatic and visceral solitary fibrous tumors in the abdomen and pelvis: cross-sectional imaging spectrum. Radiographics 2011 MarApr;31(2):393-408.

10. Sun J, Yu XR, Shi BB, Zheng J, Wu JT. CT features of retroperitoneal solitary fibrous tumor: report of three cases and review of the literature. World J SurgOncol. 2014 Oct 28;12(1):1-5.

11. Rha SE, Byun JY, Jung SE, Chun HJ, Lee HG, Lee JM. Neurogenic tumors in the abdomen: tumor types and imaging characteristics. Radiographics 2003 Jan-Feb;23(1):29-43.

12. Tchernev G, Chokoeva AA, Patterson JW, Bakardzhiev I, Wollina U, Tana C. Plexiform Neurofibroma: A Case Report. Medicine (Baltimore) 2016 Feb;95(6):1-3.

13. Bass JC, Korobkin M, Francis IR, Ellis JH, Cohan RH. Retroperitoneal plexiform neurofibromas: CT findings. AJR Am J Roentgenol 1994 Sep;163(3):617-20.

14. Shanbhogue AK, Fasih N, Macdonald DB, Sheikh AM, Menias CO, Prasad SR. Uncommon primary pelvic retroperitoneal masses in adults: a pattern-based imaging approach. Radiographics 2012 May-Jun;32(3):795817.

15. Afuwape OO, Ogundoyin OO, Ogunlana DI, and Adeleye AO. Adult Sacrococcygeal Teratoma: A Case Report. Ghana Med J. 2009 Mar;43(1):40-42.

16. Monteiro M, Cunha TM, Catarino A, Tomé V.Case report: sacrococcygeal teratoma with malignant transformation in an adult female: CT and MRI findings.Br J Radiol 2002 Jul;75(895):620-3.

17. Hirasaki S, Kanzaki H, Okuda M, Suzuki S, Fukuhara T, Hanaoka T. Composite paraganglioma-ganglioneuroma in the retroperitoneum. World J Surg Oncol. 2009 Nov;7(1)81.

18. Inzani F1, Rindi G, Tamborrino E, Cobelli R, Bordi C. Extra-adrenal composite paraganglioma with ganglioneuroma component presenting as a pancreatic mass. Endocr Pathol. 2009 Fall;20(3):191-5. 